\title{
Ventricular tachycardia and exercise related syncope in children with structurally normal hearts: emphasis on repolarisation abnormality
}

\author{
Chung Il Noh, Jin Young Song, Ho Sung Kim, Jung Yun Choi, Yong Soo Yun
}

\begin{abstract}
Objective-To emphasise the importance of ventricular tachycardia associated with repolarisation abnormality in syncope associated with exercise.

Design-Retrospective analysis of data on children presenting with syncope between 1985 and 1993.

Patients-5 apparently normal children with recurrent exercise related syncope associated with electrocardiographically abnormal TU complexes.

Results-3 children were diagnosed as having an intermediate form of the long QT syndrome and catecholamine sensitive ventricular tachycardia because the abnormal TU complexes were associated with polymorphic ventricular tachycardia that was not typical of torsades de pointes. Tachycardia was induced by exercise in all patients and by isoprenaline in the one patient who was tested. One patient also had sinus node dysfunction. One child had incessant salvos of polymorphic ventricular arrhythmias and intermittent abnormal TU complexes suggestive of repolarisation abnormalities. The other had typical congenital long QT syndrome. Treatment was effective in three patients; two patients took a $\beta$ blocker alone and one took a $\beta$ blocker and low doses of amiodarone. One patient died suddenly, death being associated with sinus node dysfunction. In one patient with incessant ventricular arrhythmias treatment with a $\beta$ blocker, amiodarone, or Ic drugs was ineffective and always associated with proarrhythmia or syncope. He was not given further treatment and was asymptomatic despite having mild cardiomegaly.
\end{abstract}

Conclusions-Ventricular tachycardia associated with repolarisation abnormality was an important cause of exercise related syncope in apparently normal children. TU complex abnormalities can be identified by repeated electrocardiography. $\beta$ Blockers are effective in preventing recurrent episodes. The role of amiodarone in this type of ventricular tachycardia needs further evaluation.

(Br Heart f 1995;73:544-547)

Keywords: ventricular tachycardia; exercise; syncope; repolarisation; children
Although most syncope in childhood is related to reflexes, ${ }^{1}$ few children have recurrent episodes and are at risk of sudden death. A history of exercise related syncope generally indicates that syncope is not simple and benign and is likely to be of cardiac origin. ${ }^{2}$ Routine surface electrocardiography has been regarded as an adequate screening test to rule out cardiac arrhythmias as the cause of syncope in children with structurally normal hearts. Routine surface electrocardiography may, however, give negative results in cases of intermittent arrhythmia or intermittent electrocardiographic changes before the onset of arrhythmia. Generally, routine electrocardiography gives normal results in cases of syncope due to ventricular arrhythmia. ${ }^{2}$

We reviewed our recent cases of exercise related syncope in children with structurally normal hearts to investigate the role of ventricular tachycardia associated with repolarisation abnormality.

\section{Patients and methods}

We reviewed the records of the patients who presented with syncopal episode at the Seoul National University Children's Hospital between 1985 and 1993. Only patients with history of recurrent exercise related syncope were selected for analysis.

Five patients had a history of recurrent episodes of exercise related syncope. Their ages at presentation ranged from 2 to 10 years. All were boys.

\section{Results}

The table gives the clinical data and outcome for each of the five children.

\section{PRESENTING FEATURES}

Four children presented with syncope during exercise. The other presented with seizure during exercise. In two children syncope was also related to fright. One had recovered from a cardiac arrest. Three had been treated for epilepsy.

\section{SURFACE ELECTROCARDIOGRAPHY}

Routine surface electrocardiograms showed normal QRS complexes in all cases. The QTc interval was normal in two children and prolonged in three. In one child the initially normal QTc interval became prolonged as sinus node function deteriorated. One child with a normal QTc interval in most of the recordings showed abnormal TU complexes 
Data on each of the five cases

\begin{tabular}{|c|c|c|c|c|c|c|c|}
\hline $\begin{array}{l}\text { Case } \\
\text { No }\end{array}$ & Sex & $\begin{array}{l}\text { Age at } \\
\text { presentation } \\
(y)\end{array}$ & $\begin{array}{l}\text { Clinical } \\
\text { features }\end{array}$ & $\begin{array}{l}\text { Electrocardiographic } \\
\text { results }\end{array}$ & $\begin{array}{l}\text { Associated } \\
\text { arrhythmia }\end{array}$ & $\begin{array}{l}\text { Exercise induced } \\
\text { tachycardia }\end{array}$ & Outcome \\
\hline 1 & $\mathbf{M}$ & 10 & Syncope & Normal & $\begin{array}{l}\text { Infrequent premature } \\
\text { ventricular contraction }\end{array}$ & Yes & $\begin{array}{l}\text { Well taking } \\
\beta \text { blocker }\end{array}$ \\
\hline 2 & $\mathbf{M}$ & 5 & Syncope & $\begin{array}{l}\text { Intermittent abnormal } \\
\text { TU complex }\end{array}$ & $\begin{array}{l}\text { Incessant premature } \\
\text { ventricular contraction, } \\
\text { couplets, polymorphic } \\
\text { ventricular tachycardia }\end{array}$ & No & $\begin{array}{l}\text { Well without } \\
\text { treatment; } \beta \\
\text { blocker, amiodarone, } \\
\text { propafenone, } \\
\text { flecainide ineffective }\end{array}$ \\
\hline 3 & $M$ & 6 & $\begin{array}{l}\text { Chest pain, } \\
\text { syncope, } \\
\text { cardiac arrest }\end{array}$ & $\begin{array}{l}\text { Sinus bradycardia, } \\
\text { QTc }=0.61 \mathrm{~s}\end{array}$ & $\begin{array}{l}\text { Frequent premature ventricular } \\
\text { contraction, couplets, } \\
\text { polymorphic ventricular } \\
\text { tachycardia, sinus } \\
\text { dysfunction }\end{array}$ & Yes & $\begin{array}{l}\text { Died; } \beta \text { blocker and } \\
\text { phenytoin ineffective }\end{array}$ \\
\hline 4 & $\mathbf{M}$ & 6 & Seizure & $\mathrm{QTc}=0.51 \mathrm{~s}$ & $\begin{array}{l}\text { Infrequent premature ventricular } \\
\text { contraction }\end{array}$ & Yes & $\begin{array}{l}\text { Well taking } \beta \text { blocker } \\
\text { and low dose } \\
\text { amiodarone }\end{array}$ \\
\hline 5 & $\mathbf{M}$ & 2 & Syncope & $\begin{array}{l}\mathrm{QTc}=0.55 \mathrm{~s} \\
\mathrm{~T} \text { alternans }\end{array}$ & No & $\mathrm{No}^{\star}$ & $\begin{array}{l}\text { Well taking large doses of } \\
\beta \text { blocker; } \beta \text { blocker } \\
\text { and } \\
\text { low dose amiodarone }\end{array}$ \\
\hline
\end{tabular}

${ }^{\star}$ Level of exercise not sufficient to induce tachycardia
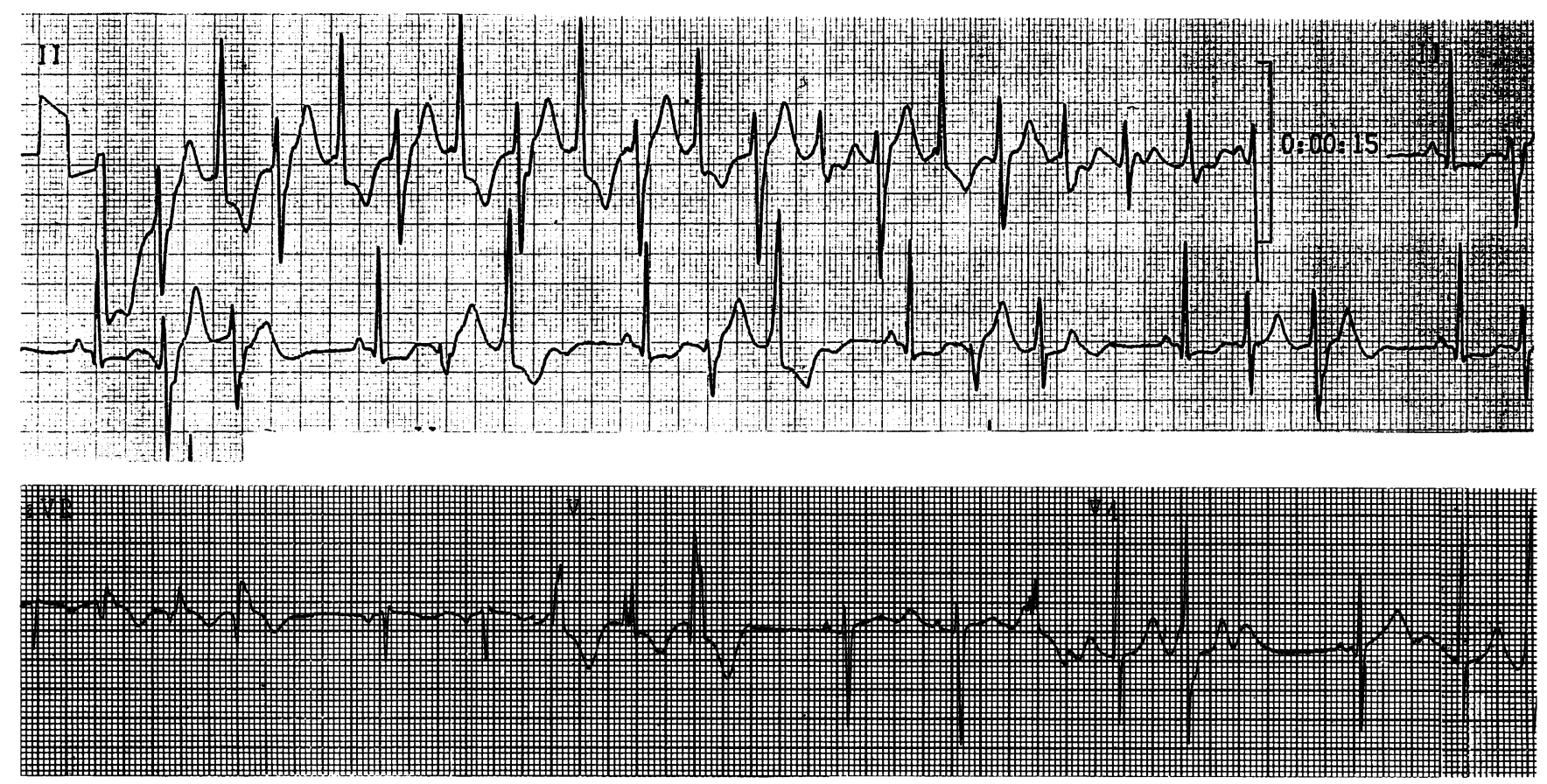

Figure 1 Surface electrocardiograms in case 2. Top: ventricular arrhythmia persisting day and night. Bottom: Prolonged and abnormal TU complexes after sinus and non-sinus QRS complexes suggestive of repolarisation abnormality were recorded.

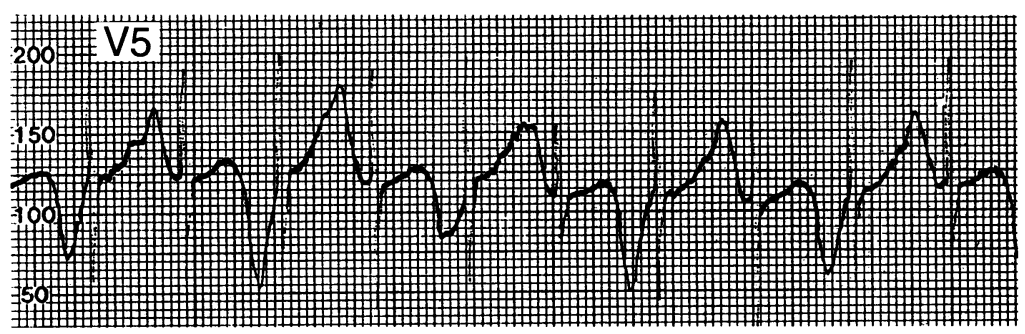

Figure 2 Surface electrocardiogram on Holter monitoring in case 5. Both abnormal TU complexes and $T$ alternans were recorded. intermittently. These changes were not directly related to the onset of the ventricular arrhythmias (figure 1 (bottom)).

\section{ASSOCIATED RHYTHM DISTURBANCES}

On Holter monitoring infrequent premature ventricular contractions were detected in two children; incessant salvos of ventricular arrhythmias with bigeminy, couplets, and polymorphic ventricular tachycardia in one child (case 2; figure 1) and frequent episodes of ventricular premature contractions, couplets, and polymorphic ventricular tachycardias along with moderate sinus bradycardia in the other (case 3). In one child with the long QT syndrome (case 5) only $T$ alternans without ventricular arrhythmia was recorded (figure 2). 
Figure 3 Surface electrocardiogram during exercise in case 3 tachycardia with

bidirectional pattern was induced at stage 1 of exercise test.
Polymorphic ventricular

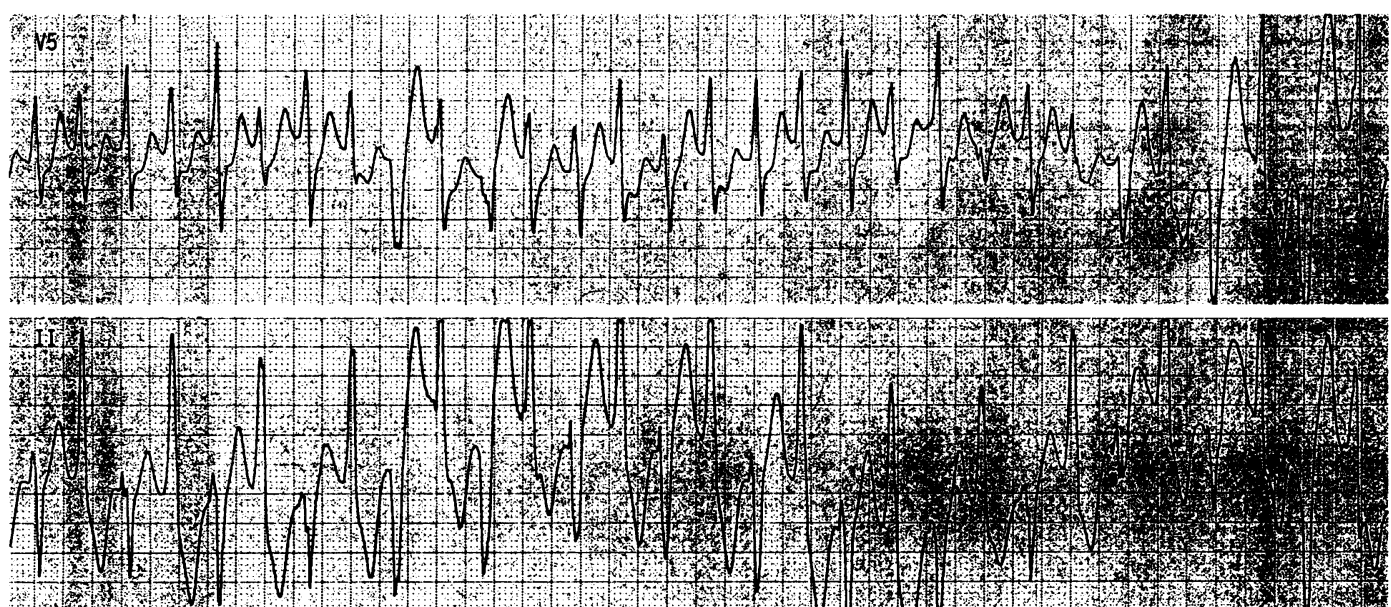

INDUCTION OF VENTRICULAR ARRHYTHMIAS

Polymorphic ventricular tachycardias with a bidirectional pattern were induced in three children (in cases 1 and 3 on exercise testing and in case 4 on Holter recording during exercise) (figure 3). Ventricular tachycardia and abnormal TU complexes were also induced on infusion of isoprenaline in case 1 during the electrophysiological study (figure 4). In case 2, which had incessant ventricular arrhythmias, exercise testing did not aggravate ventricular arrhythmia. In case 5 (that of the youngest child, who had the idiopathic long QT syndrome) exercise was not sufficient to provoke tachycardia.

\section{OUTCOME}

One child (case 3 ) died suddenly in the morning in his classroom. He was taking nadolol $(0.5 \mathrm{mg} / \mathrm{kg} /$ day $)$ and phenytoin $(5 \mathrm{mg} / \mathrm{kg} /$ day $)$ and had persistent dizziness on exercise.

Two children (cases 4 and 5) were treated with atenolol $(1.2 \mathrm{mg} / \mathrm{kg} /$ day and 3.0
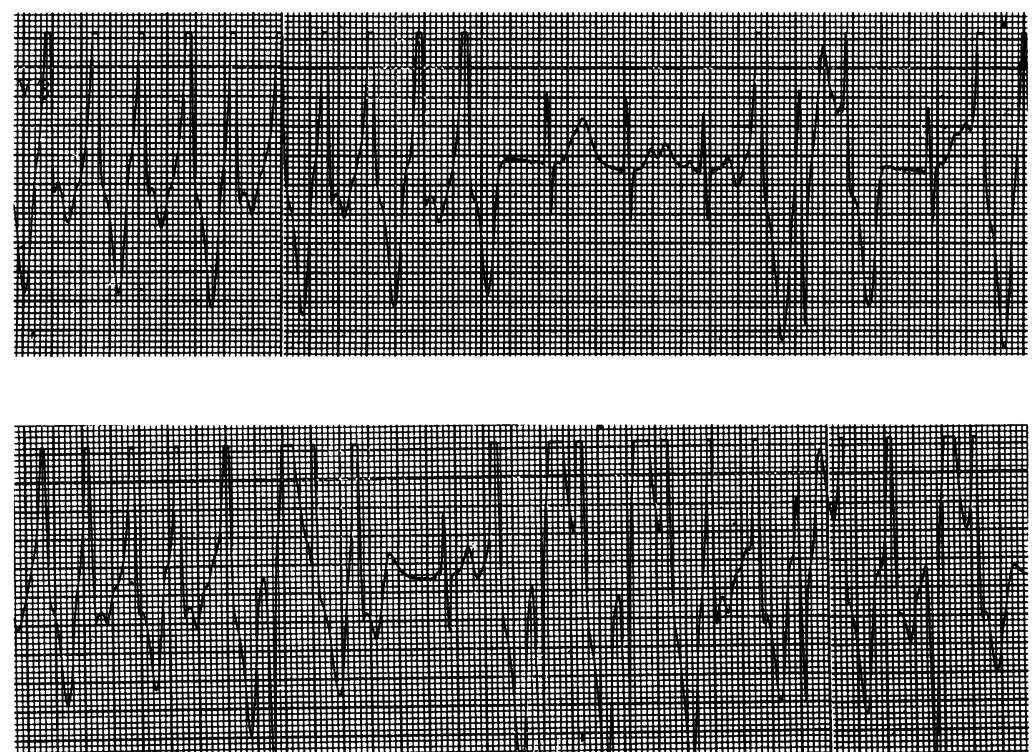

Figure 4 Continuous electrocardiogram of induced ventricular tachycardia in case 1 during electrophysiological test while patient was taking isoprenaline. Top: Abnormal TU complexes after narrow $Q R S$ complexes. Bottom: Ventricular tachycardia with bidirectional pattern. $\mathrm{mg} / \mathrm{kg} /$ day). In case 5 low doses of amiodarone $(2 \cdot 5 \mathrm{mg} / \mathrm{kg} /$ day $)$ were tried temporarily as syncope was not completely suppressed by atenolol $2.5 \mathrm{mg} / \mathrm{kg} /$ day. Although QTc interval was not prolonged $(0.55$ to $0.49 \mathrm{~s})$ and the child became more active with amiodarone, amiodarone was discontinued for fear of proarrhythmia and atenolol was increased to $3 \mathrm{mg} / \mathrm{kg} /$ day. In case 4 a $\beta$ blocker and a low dose of amiodarone $(3 \mathrm{mg} / \mathrm{kg} /$ day) were given because ventricular tachycardia was partially controlled by propranolol. Treatment with $\beta$ blocker, amiodarone, or Ic drugs (flecainide, propafenone) was ineffective and associated with proarrhythmias (syncope, torsades de pointes, faster ventricular rate) in one child with incessant ventricular arrhythmias (case 2).

He was followed up while not taking any drugs for seven years. Although there was mild cardiomegaly on chest radiography, he was symptom free and as active as his peers.

\section{Discussion}

When syncope is atypical-for example, when it is related to exercise or stress, is recurrent, has a sudden onset without premonitory symptoms, occurs while the patient is recumbent, and is of long duration -it is unlikely to be simple fainting. ${ }^{2}$ A history of exercise related syncope suggests cardiac causes, ${ }^{2}$ and sudden death in a high risk subgroup is commonly provoked by exercise. ${ }^{1}$ When the syncope has an abrupt onset it may be caused by dysrhythmia. ${ }^{1}$ Among children with exercise related syncope, the most common cause is ventricular tachycardia. ${ }^{3}$ Endogenous catecholamines could induce ventricular tachycardia during exercise or anxiety in a child with an apparently normal heart. ${ }^{4}$ Although the long QT syndrome is well known clinically for causing exercise related or stress related ventricular tachycardia and syncope, some patients have a normal QT interval and develop severe ventricular tachycardia on exercise or with stress without having abnormal hearts. ${ }^{56}$ Unlike those with the idiopathic long QT syndrome, this group of patients has consistently normal TU complexes. ${ }^{5}$ When heart rate increases during exercise induced 
premature ventricular contractions become polymorphic ventricular tachycardia, which is sometimes bidirectional. If exercise persists such tachycardia may proceed to ventricular fibrillation, which is rarely typical of torsades de pointes. ${ }^{7} \beta$ Blockers are effective in this type of ventricular tachycardia. ${ }^{5-7}$

Ventricular tachycardia typical of the long QT syndrome is torsades de pointes. It is important to identify the cause because of the association with sudden death in this syndrome. Usually the long QT syndrome can be recognised by clinical features and in surface electrocardiograms. ${ }^{8}$ However, the QT interval and TU complex may be normal at rest and become abnormal before the onset of ventricular arrhythmia. ${ }^{9}$ Three of our cases (cases 1, 3, and 4) might be an intermediate form between catecholamine sensitive ventricular tachycardia and the long QT syndrome. ${ }^{1011}$ Polymorphic ventricular tachycardia with a bidirectional pattern, rather than torsades de pointes, was induced with exercise or isoprenaline infusion; the QTU complex was abnormal at rest or with stress. Sinus node dysfunction also occurred in case 3 . In case 5 , $\mathrm{T}$ alternans supported the idiopathic long QT syndrome, even though ventricular tachycardia was not recorded as a cause of syncope. In case 2 abnormal TU complexes were recorded intermittently. Since the onset of ventricular arrhythmias was not preceded by the abnormal TU complexes, case 2 may be another type of polymorphic ventricular tachycardia, ${ }^{11}$ rather than a variant of the long QT syndrome. This case is different from the others in several aspects: many antiarrhythmic drugs, including $\beta$ blockers, were ineffective and caused proarrhythmias; apart from the first few episodes, the patient was free of symptoms without being treated; he was as active as his peers; and the mild cardiomegaly in chest radiographs suggested that the ventricular arrhythmias had affected his cardiac function during follow up. Because he did not undergo the invasive study we cannot say for sure that his heart was normal. Abnormal TU complexes suggested, however, that the repolarisation disturbance was a possible mechanism of ventricular arrhythmia in this case, whatever the underlying cause.

The relation of bidirectional ventricular tachycardia to the typical long QT syndrome is not clear. Polymorphic ventricular tachycardia with an alternating QRS axis may precede typical torsades de pointes. ${ }^{6}$ Bidirectional ventricular tachycardia can develop in association with prolonged QT interval. ${ }^{511}$ If ventricular tachycardia with QRS complexes of an alternating axis occurs in the long QT syndrome the mechanism of ventricular tachycardia may be the same as that of torsades de pointes. Bidirectional ventricular tachycardia which is not related to prolonged QT interval has been described. ${ }^{12}$ Three cases of this intermediate form of ventricular tachycardia may be said to conform broadly with the classification "long QT syndrome".

The use of amiodarone in the adrenergic long QT syndrome is controversial. Further prolongation of QT interval by amiodarone in the syndrome is generally regarded as harmful, and this drug is to be avoided. Amiodarone is known to cause torsades de pointes. ${ }^{13}$ However, amiodarone may reduce the variability in the refractory period in the ventricular myocardium and maintain an antiarrhythmic effect despite prolonging the QT interval. ${ }^{14}$ There is a report of the successful use of amiodarone in the long QT syndrome. ${ }^{15}$ In cases 4 and 5 of our study QTc interval did not increase $(0.51 \mathrm{~s}$ to $0.49 \mathrm{~s}$ and $0.55 \mathrm{~s}$ to $0.49 \mathrm{~s}$ ) when amiodarone was given with a $\beta$ blocker, and the children became more active without developing symptoms. These experiences suggest that amiodarone could be used if it does not prolong the QT interval much and that cautious use of amiodarone is another option in cases intractable to $\beta$ blockers.

In conclusion, although recurrent exercise related syncope is rare in children, it is important to define the cause clearly to prevent death. We found that ventricular tachycardia related to repolarisation abnormality was an important cause. $\beta$ Blockers are effective in preventing recurrent episodes.

This study was partly supported by the Seoul National University Children's Hospital Research Fund.

1 Ruckman RN. Cardiac causes of syncope. Pediatr Rev 1987;9:101-8.

2 O'Laughlin MP, McNamara DG. Syncope. In: Garson A $\mathrm{Jr}$, Bricker JT, McNamara DG, eds. The science and practice of pediatric cardiology. Philadelphia: Lea and Febiger, 1990:1929-46.

3 Garson A Jr. Ventricular arrhythmias. In: Garson A Jr, Bricker JT, MacNamara DG, eds. The science and practice of pediatric cardiology. Philadelphia: Lea and Febiger, 1990:1888.

4 Horan M, Venables AW. Paroxysmal tachycardia with episodic unconsciousness. Arch Dis Child 1962;37:82-5.

5 von Bernuth G, Bernsau U, Gutheil $\mathrm{H}$, et al. Tachyarrhythmic syncope in children with structurally normal hearts with and without QT-prolongation in the normal hearts with and without QT-prolongation in

6 Shaw TRD. Recurrent ventricular fibrillation associated with normal QT intervals. Qf Med 1981;200:451-62.

7 Coumel P, Fidelle J, Lucet V, Attuel P, Bouvrain Y. Catecholamine-induced severe ventricular arrhythmias with Adams-Strokes syndrome in children. Report of four cases. Br Heart $\mathcal{F}$ 1978;40:28-37.

8 Schwartz PJ, Moss AJ, Vincent GM, Crampton RS Diagnostic criteria for the long QT syndrome. An update. Circulation 1993;88:782-4

9 Jackman WM, Friday KJ, Anderson JL, Aliot EM, Clark $M$, Lazzara $R$. The long QT syndromes. A critical review, new clinical observations and a unifying hypothesis. Prog Cardiovasc Dis 1988;31:115-72.

10 Haissaguerre $M$, Warin JF, Veaux $P$, Le-Metayer $P$, Guillem JP, Blanchot $P$. Tachycardie ventriculaire catecholergique: A propos d'un cas avec anomalies associées de l'intervalle QTu. Ann Cardiol Angeiol (Paris) 1987; 36:19-22.

11 Glikson M, Constantini N, Graftstein Y, Kaplinsky E, Eldar M. Familial bidirectional ventricular tachycardia. Eldar M. Familial bidirection

12 Cohen TJ, Liem LB, Hancock EW. Association of bidirectional ventricular tachycardia with familial sudden death tional ventricular tachycardia with familial

13 Barthelemy M, Lionnet F. Torsades de pointes during loading with amiodarone. Eur Heart $\mathcal{F}$ 1987;8:541-3.

14 Surawicz B, Knoebel SB. Long QT: good, bad or indifferent? $\mathcal{F}$ Am Coll Cardiol 1984;4:398-413.

15 Gururaj AK, Ainon S. Effective management of long QT syndrome with amiodarone. $\mathcal{F}$ Singapore Paediatr Soc 1990;32:50-2. 